\title{
AOR
}

Selected Papers of \#AolR2021:

The 22nd Annual Conference of the

Association of Internet Researchers

Virtual Event / 13-16 Oct 2021

\section{"THE GREAT YOUTUBE PURGE OF WRONGTHINK": ALTRIGHT ADAPTATIONS IN A CHANGING PLATFORM ECOLOGY}

Scott Burnett

University of Gothenburg

Fotini Paleologou Moura Trancoso

University of Gothenburg

\section{Introduction and Approach}

Social media companies stand accused of having facilitated the "radicalization" of the young, white men associated with the "manosphere" (Ging, 2019) and with far-right movements online (Conway, 2017; Johnson, 2018). As many platforms attempt to tighten their moderation practices and terms of service in order to close down "independent" spaces for extremism, originators of these discourses evolve in response.

In this paper, we investigate how a Swedish AltRight YouTuber successfully adapts to his changing environment, and we argue for the importance of understanding how ideologies of hate behave under pressure.

YouTube has been an important vector of extremism that until quite recently positioned itself as a neutral, open hosting service that took minimal responsibility for the content of user posts (Lewis, 2018). This laissez-faire approach to political content, combined with an algorithm that promoted similar content, saw YouTube emerge as the backbone of the "Alternative Influence Network" (AIN) which builds the relatability, authenticity, and accountability of far-right "micro-celebrity" figures (Lewis, 2018, 2020). By 2018, calls were coming in from a number of sectors for YouTube to "govern content and behavior for explicit values" (Lewis, 2018, p. 44). The focus on values here moves on from the focus on specific slurs or racial calumnies, which are already easy to avoid in the highly coded, ironic registers of the AltRight (Askanius, 2021).

One member of the AIN identified by Lewis (2018) is Swedish white nationalist Marcus Follin. His "The Golden One" (TGO) channel is not the most popular AltRight account, but articulates a novel mix of health, fitness, self-help, and neo-Nazi ideology that repays careful discourse analysis. While a number of other nodes in the AIN - including

Suggested Citation (APA): Burnett, Scott and Trancoso, Fotini Paleologou Moura. (2021, October). “'The Great YouTube Purge of Wrongthink': AltRight adaptations in a changing media ecology". Paper presented at AolR 2021: The 22nd Annual Conference of the Association of Internet Researchers. Virtual Event: AolR. Retrieved from http://spir.aoir.org. 
Richard Spencer and Stefan Molyneux - have been shut down since YouTube tightened their rules, TGO has endured, and grown his subscriber base from 96,000 to 111,000 . His approach to fitspiration, self-help, white nationalism (including Nazi symbology) and positivity (see Strick, 2020) is highly coded, and even esoteric. He operates his channel as the central content hub for a number of online businesses, selling personal training, fitness supplements, coffee, and clothing. TGO represents the confluence of a number of contemporary discourses: the neoliberal individualism endemic to self-help culture, the figure of the "influencer" in online attention economies (Hund, 2019), and the wry humour and multimodal creativity of so-called "Fascism 2.0" (Fuchs, 2017). We refer to the role he plays in the masculinist and anti-feminist world of the manosphere as that of a "manfluencer".

We used multimodal discourse analysis, grounded in a postfoundational approach (see Marttila, 2016) to analyse a corpus of 22 TGO videos posted on his channel between June 2019 and March 2021 in which the policies and actions of social media platforms to ban (or "shadow ban") far right figures is explicitly thematized.

\section{Data and Analysis}

Key themes we identified in our analysis include:

Cultural encryption: TGO adopts Marxian/Gramscian-inspired theories of the relationship between politics and culture to explain to his subscribers how "Leftists" have succeeded dominating various social and political institutions. He understands himself and his followers as engaged in a "metapolitical" war for the West, for whiteness, and masculinity. In critiquing what he calls the YouTube "Great Purge of Wrongthink" he offers advice on crafting content and memes that will not be defined as hate-speech in order to not be "defeated" on platforms such as YouTube. His already esoteric invocation of Nordic mythology, as well as the characters and narratives of historical, gaming, and fictional narratives, as well as layers of irony and self-mockery, represent increasingly opaque codes designed to protect in-groups from external scrutiny.

Partial articulations: TGO repeatedly emphasizes his challenge to social media "censors" to show him exactly how he has broken their terms of service. He articulates his politics as a politics of love, doubling down on positive characterizations of the West, of white nations, and "population genetic" arguments about the dangers of the "Great Replacement" without explicitly naming the force behind it. He represents himself as focusing on white male health and wellness, without attacking out-groups. He does admit that if he were to speak openly, he could be prosecuted in Sweden for "hets mot folkgrupp" (inciting violence against an ethnic group). He openly wears neo-Nazi symbols and invokes arcane anti-Semitic and racist tropes. But his "metapolitical" strategy and references to a "Crusade" consistently avoid blatant negativity, or the promotion of specific acts of violence.

Platform diversification: The most significant strategy evident in the TGO corpus is an increasing platform-specific content strategy. He informs his viewers that he will continue to post "light-hearted" content on YouTube while he will cover political content 
on Gab, Telegram, and his podcasts. He is explicit in articulating a multiplatform ecology for the TGO brand that segments the kinds of political speech he will engage in by platform and user agreements, while consistently hyperlinking between his various holdings in order to build his audience across platforms, building a strategy for a resilient and distributed online presence.

\section{Preliminary Conclusions}

From our initial analysis it seems that while YouTube's efforts to reduce rightwing extremism has had an impact on explicitly racist articulations, they have not necessarily diminished the profile, nor the popularity, of micro-celebrity "manfluencers" such as TGO. By characterizing social media platforms as politicized territories won by the "Left", TGO integrates his political diagnosis of the decline of Western civilization into setbacks without losing face, and indeed continues to build an audience, maintain business operations, and show signs of improved resilience. This is not a reason to roll back YouTube account restrictions, but rather for understanding the specific evolutionary pressures they exert.

\section{References}

Askanius, T. (2021). On Frogs, Monkeys, and Execution Memes: Exploring the HumorHate Nexus at the Intersection of Neo-Nazi and Alt-Right Movements in Sweden. Television \& New Media, 22(2), 147-165. https://doi.org/10.1177/1527476420982234

Conway, M. (2017). Determining the Role of the Internet in Violent Extremism and Terrorism: Six Suggestions for Progressing Research. Studies in Conflict \& Terrorism, 40(1), 77-98. https://doi.org/10.1080/1057610X.2016.1157408

Fuchs, C. (2017). Fascism 2.0: Twitter Users' Social Media Memories of Hitler on his 127th Birthday. Fascism, 6(2), 228-263. https://doi.org/10.1163/22116257-00602004

Ging, D. (2019). Alphas, Betas, and Incels: Theorizing the Masculinities of the Manosphere. Men and Masculinities, 22(4), 638-657. https://doi.org/10.1177/1097184X17706401

Hund, E. D. (2019). The Influencer Industry: Constructing And Commodifying Authenticity On Social Media [Doctor of Philosophy, University of Pennsylvania]. https://core.ac.uk/download/pdf/289184334.pdf

Johnson, J. (2018). The Self-Radicalization of White Men: "Fake News" and the Affective Networking of Paranoia. Communication, Culture and Critique, 11(1), 100115. https://doi.org/10.1093/ccc/tcx014

Lewis, R. (2018). Alternative Influence: Broadcasting the Reactionary Right on YouTube (Media Manipulation Research Initiative, p. 61) [Research Report]. Data \& Society Research Institute. 
Lewis, R. (2020). "This Is What the News Won't Show You": YouTube Creators and the Reactionary Politics of Micro-celebrity. Television \& New Media, 21(2), 201-217. https://doi.org/10.1177/1527476419879919

Marttila, T. (2016). Post-foundational discourse analysis: From political difference to empirical research. London: Palgrave Macmillan.

Strick, S. (2020). The Alternative Right, Masculinities, and Ordinary Affect. In G. Dietze \& J. Roth (Eds.), Right-Wing Populism and Gender: European Perspectives and Beyond (pp. 207-230). Bielefeld: Transcript Verlag. 